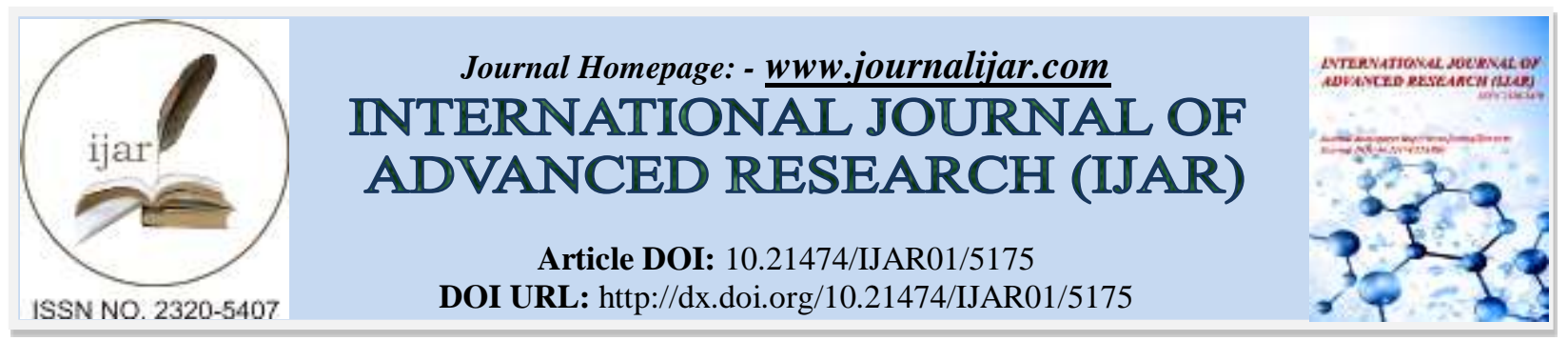

RESEARCH ARTICLE

\title{
UNDERSTANDING THE ROLE OF AYURVEDA PANCHAKARMA THERAPY W.S.R. TO VASTHI (ENEMA) IN THE MANAGEMENT OF TYPE II DIABETES MELLITUS- A CASE REVIEW.
}

Dr. Deepty Nair.

Assistant Professor, Department of Swasthavritta, Ahalia Ayurveda Medical College, Palakkad, Kerala.

\section{Manuscript Info}

Manuscript History

Received: 14 June 2017

Final Accepted: 16 July 2017

Published: August 2017

\section{Abstract}

Diabetes Mellitus has grown to a status of global epidemic. Besides the compromise on the quality of life of the patients, the socio-economic burden levied upon by this condition is also quite challenging. The global acceptance of alternative system of medicines has shown a substantial increase in the recent years. Ayurveda, as an alternative medicine, has a definite support to offer in Diabetes Mellitus (DM). Ayurveda identifies Diabetes Mellitus as not a mere increase in the blood glucose levels. Rather it a wide spectrum of clinical pathogenesis and symptomatology originating at the urinary system which can later include any physiological system. Thus, the approach of Ayurveda in the management of DM stands far beyond mere glucose control.

The present work represents the importance of classically indicated Ayurveda purificatory therapy in the management of various clinical presentations of DM. Mental stress being an identified impact factor in the pathogenesis of DM, was taken due care of while planning the therapy. A considerable control on the clinical symptomatology was achieved at the end of the therapy.

Copy Right, IJAR, 2017,. All rights reserved.

\section{Background:-}

The social and economic burden due to type II Diabetes Mellitus (DM) is increasing alarmingly ${ }^{1}$. The acceptance of Ayurveda as an alternative system of medicine for DM is also increasing globally. However, achieving a normal blood glucose level alone does not define a successful diabetic management. Rather, it includes challenges like improvement in clinical symptoms, metabolism and overall quality of life.

In Ayurveda, DM is accommodated under the disease head of Prameha. The above said challenges are addressed duly in Ayurveda. Besides effective formulations for regulating the blood glucose levels, the panchakarma therapies (purificatory therapies) have been given prime importance in the management of Prameha ${ }^{2}$.

The present work was to understand the role of Panchakarma chikitsa w.s.r. to Vasthi chikitsa (enema therapy) in the management of Prameha vis-à-vis DM.

\section{Methods and Observations:-}

The present work is a review of two cases that presented with type II DM and were subjected to Vasthi as Shodhana chikitsa alongwith other samana therapies. 
Case 1: Patient aged 63 years who was a retired BSNL employee, presented with uncontrolled type II DM since 6 months associated with weight loss, polyuria and sleep disturbance. Patient also reported considerable levels of mental stress. The patient was not taking any other medications for the present illness.

The patient was prescribed classical Prameha hara (anti-diabetic) formulations including Nisakathakadi Kashaya and Mehaghna Churna and was advised to visit for review after one month. The physical symptoms, FBS and PPBS were effectively controlled with medications and he continued this for three months. However, even on the third monthly review no significant change was observed in the HbA1c. The patient was admitted in IPD and an Ayurveda panchakarma protocol including Abhyanga, Takra dhara and Yoga vasthi with a total duration of 8 days was administered. At the end of the therapy HbAlc was observed to be significantly improved from $12.5 \%$ to $10.6 \%$.

Case 2: Patient aged 36 years, driver by profession, presented with uncontrolled type II DM since 1 year associated with constipated bowel, chest burn and sleep disturbance. The patient reported a considerable level of mental stress. The patient was not taking any medications for the present illness.

The patient was admitted in IPD and subjected to an Ayurveda panchakarma protocol including Abhyanga, Takradhara and Kheeravasthi with a total duration of four days along with classical Prameha hara (anti-diabeteic) internal medications. On discharge, the clinical symptoms presented were completely cured and the FBS values showed significant improvement from $260 \mathrm{mg} \%$ to $172 \mathrm{mg} \%$.

\section{Observations:-}

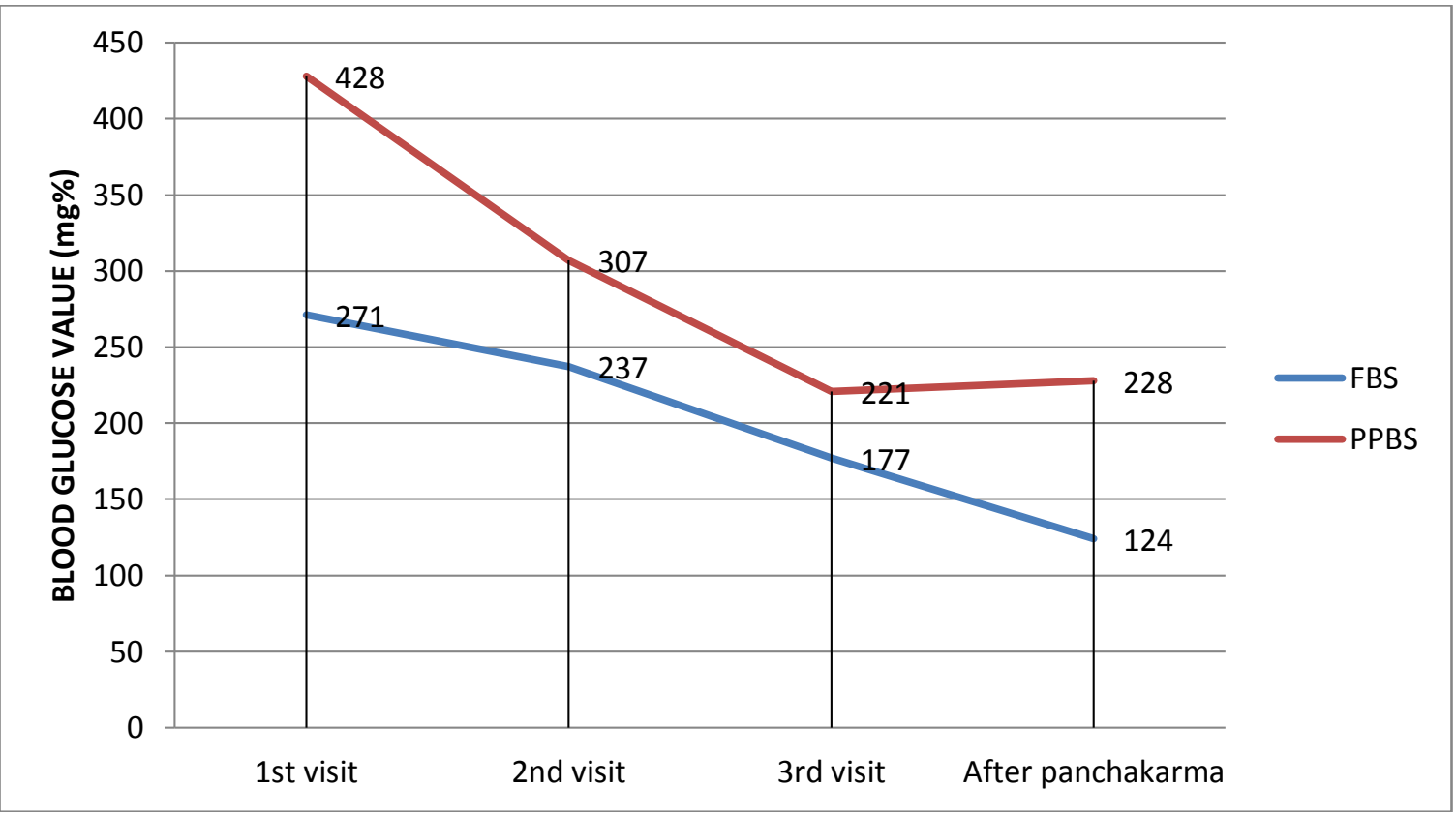

Fig 1:- Changes in FBS and PPBS values on various visits (Case 1) 


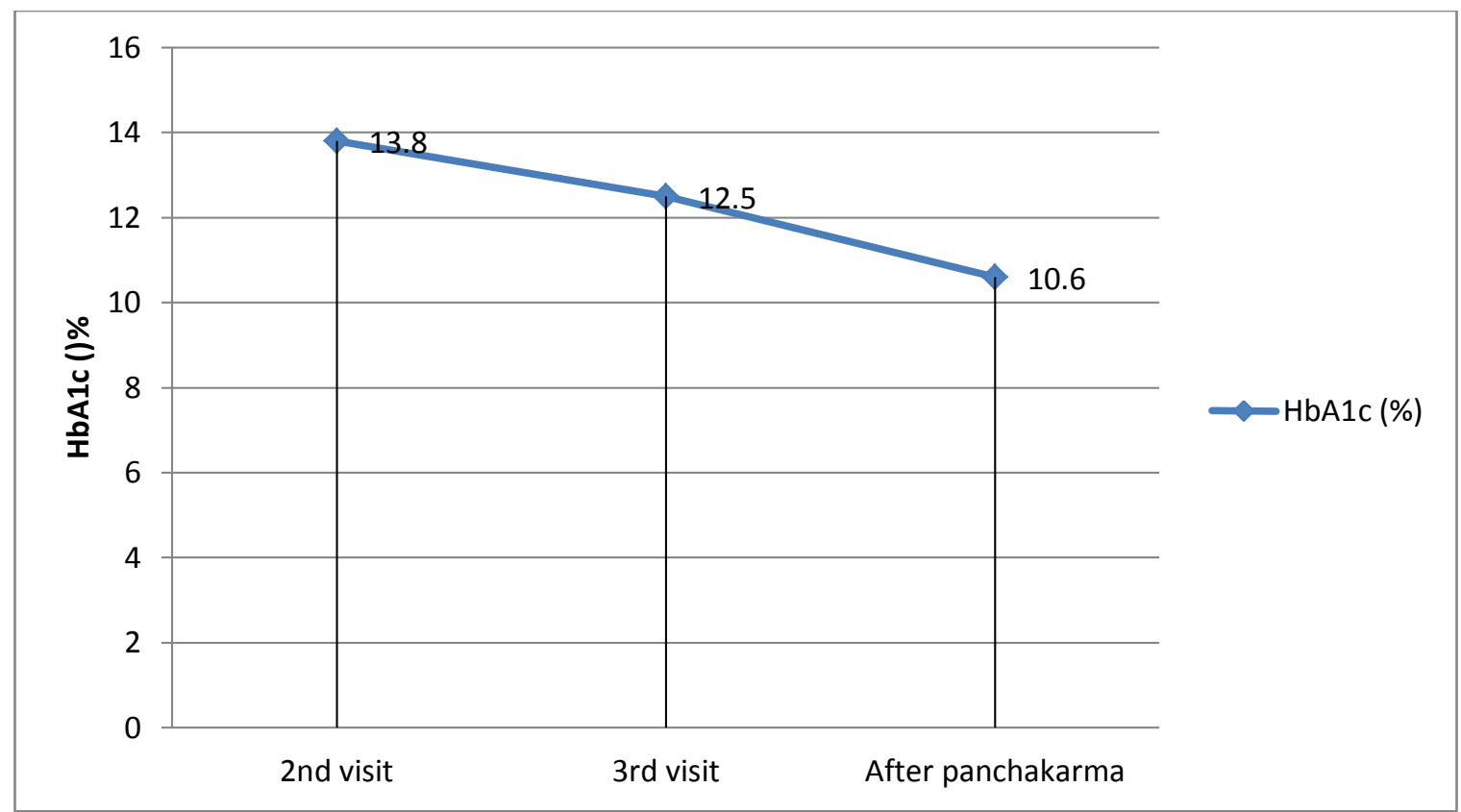

Fig 2:- Changes in HbA1c values on various visits (Case 1)

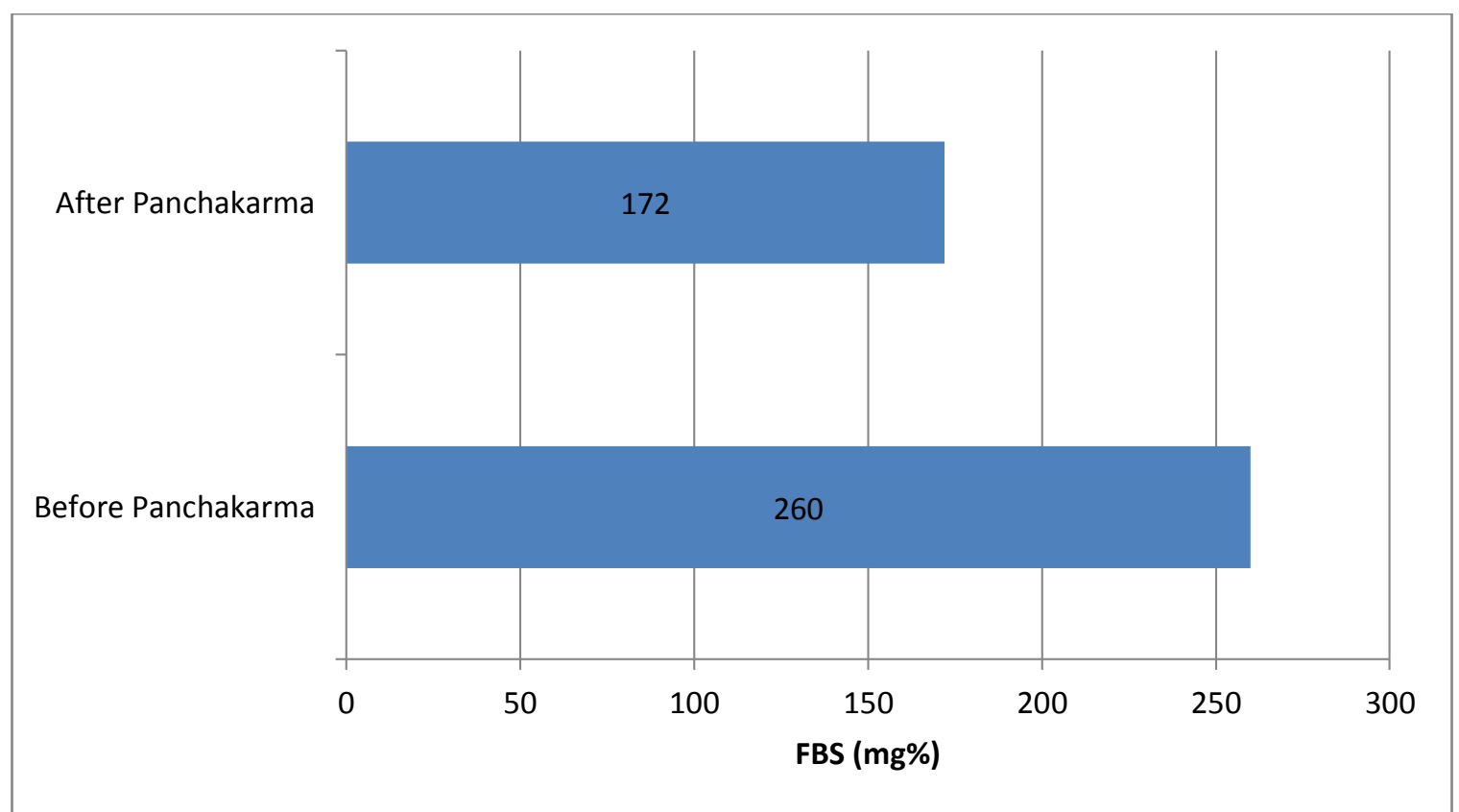

Fig 3:- Changes in FBS values before and after Panchakarma (Case 2)

\section{Discussion:-}

Ayurveda analysis of a disease is based on the concept of three humours (tridosha theory) viz. Vata, Pitta and Kapha. DM is a lifestyle disease understood primarily to be caused by metabolic disturbances due to over nourishment. However, eventually it involves various systems in the body including vision, renal function, and peripheral nervous system and precipitates a functional loss. Ayurveda also opines Prameha to be resulting from vitiated Kapha, the nourishing factor in the body. However, eventually there is an essential involvement of Vata in this disease pathology ${ }^{3}$. Moreover, both the cases presented with considerable mental stress which is an identified cause for uncontrolled $\mathrm{DM}^{4}$. Mental stress is an inevitable factor in today's lifestyle. Vata is the predominant dosha in the pathology of mental stress ${ }^{5}$. Among the various purificatory therapies suggested in Ayurveda, Vasthi is the 
best therapeutic modality suggested for controlling Vata ${ }^{6}$. Moreover, Vasthi is also considered to be the prime sodhana therapy in Ayurveda ${ }^{7,8}$. Based on this Vasthi was administered in these cases.

The results were in accordance to the classical references supporting the role of Vasthi as sodhana chikitsa for Prameha.

\section{Conclusion:-}

Based on the observations of this case study it can be concluded that Ayurveda Panchakarma therapy can yield good results in management of clinical symptoms and blood sugar values in type II Diabetes Mellitus. In particular, Vasthi as a prime purificatory therapy can be applied effectively in cases of type II Diabetes Mellitus with promising results.

\section{References:-}

1. Global report on Diabetes. World Health Organization, Geneva, 2016.

2. Sharma RK, Dash B, editors. Caraka Samihitā, Chikitsa Sthāna, English Translation. Varanasi, India: Chaukhamba Sanskrit Series Office; 2012 reprint. Vol 3. Chapter 6.Sutra 15: pg 303

3. Sharma RK, Dash B, editors. Caraka Samihitā, Chikitsa Sthāna, English Translation. Varanasi, India: Chaukhamba Sanskrit Series Office; 2012 reprint. Vol 3. Chapter 6.Sutra 52: pg 312

4. Mooy JM, De Vries H, Grootenhuis PA, Bouter LM, Heine RJ: Major stressful life events in relation to prevalence of undetected type 2 diabetes. Diabetes Care 23:197-201, 2000

5. Sharma RK, Dash B, editors. Caraka Samihitā, Sutra Sthāna, English Translation. Varanasi, India: Chaukhamba Sanskrit Series Office; 2012 reprint. Vol 1. Chapter 12.Sutra 8: pg 237-238

6. Murthy SKR, editor. Așțānga Hr̊dayam, Sūtra Sthāna, English Translation. Varanasi, India: Krishnadas Academy; 2011. Vol 1. Chapter 1. Sutra 25; pg 14

7. Murthy SKR, editor. Aștạnga Hṛdayam, Sūtra Sthāna, English Translation. Varanasi, India: Krishnadas Academy; 2011. Vol 1. Chapter 19. Sutra 64; pg 85-86

8. Sharma RK, Dash B, editors. Caraka Samihitā, Siddhi Sthāna, English Translation. Varanasi, India: Chaukhamba Sanskrit Series Office; 2012 reprint. Vol 1. Chapter 10.Sutra 4-5: pg 366-367. 